\title{
Health literacy in Beijing: an assessment of adults' knowledge and skills regarding communicable diseases
}

Daitao Zhang ${ }^{1+}$, Shuangsheng Wu ${ }^{1+}$, Yi Zhang ${ }^{1}$, Peng Yang ${ }^{1}$, C. Raina Maclntyre ${ }^{2}$, Holly Seale ${ }^{2}$ and Quanyi Wang ${ }^{1 *}$

\begin{abstract}
Background: There have been a number of studies conducted to date looking at the issue of health literacy, but none have been conducted in Beijing, China. The aim of this study was to evaluate the communicable diseases health literacy (CDHL) levels of Beijing residents towards three key areas: knowledge, adoption of preventative measures/behaviours, and health skills.

Methods: A structured survey was undertaken with Beijing residents aged $\geq 18$ years. A multistage stratified sampling approach was used to identify and recruit residents. Participants were excluded if they were foreigners, residents of Hong Kong, Macau or Taiwan, or were unable to communicate in Mandarin.

Results: The questionnaire was completed by 11052 participants, with a moderate accuracy rate (average: $61.3 \%$ ) and a good discrimination level (average: 0.428). Cronbach's alpha was 0.748. The items were grouped into three subscales representing knowledge, adoption of preventative measures and behaviours, and health skills. Correlations of the subscales and the Total Score is significant $(P<0.01)$, and all the three subscales correlate strongly with the Total Score The mean CDHL score of Beijing inhabitants was 15.28. The percentage of those who were identified as having adequate CDHL was $41 \%$.

Conclusions: The total CDHL level of residents in Beijing was relatively low, particularly in those residing in the suburbs, those above 60 years of age, manual workers, and the illiterates. Gender, age-group, level of education, occupation, self-reported health status and region were all shown to be significantly predictive of CDHL. It is important that more resources are dedicated to improving the CDHL in Beijing, given the risk of emerging and re-emerging infectious diseases in the region.
\end{abstract}

\section{Background}

The concept of health literacy is an important but complex concept, and since it was first propositioned there has been continuing debate about the definition and the approaches used to measure the levels [1-5]. The World Health Organization (WHO) defines health literacy simply as "an individual's ability to gain access to understand and use health information" for promoting and maintaining health $[6,7]$, referring to the definition of health literacy given by the National Assessment of Adult Literacy, the Institute of Medicine Committee for

\footnotetext{
* Correspondence: bjcdcxm@126.com

${ }^{\dagger}$ Equal contributors

'Beijing Center for Disease Prevention and Control, No.16 He Pingli Middle

Street, Dongcheng District, Beijing 100013, China

Full list of author information is available at the end of the article
}

Health Literacy and the American Medical Association (AMA) [8].

People with low health literacy tend to adopt fewer preventive services and less health information technology. As a result, they use emergency department more frequently, have poorer health outcomes and a higher risk of death [9-12]. It is particularly urgent to identify these community groups and to take measures to improve their CDHL.

There are a number of approaches which can be utilised to measure the "degree to which individuals and communities have the capacity to obtain, process, and understand basic health information and services needed to make appropriate health decisions" [13]. These include the Rapid Estimate of Adult Literacy in Medicine (REALM) [14], the Test of Functional Health Literacy in 
Adults (TOFHLA) [15], the Shortened Rapid Estimate of Adult Literacy in Medicine (REALM-R), the Shortened Test of Functional Health Literacy in Adults (STOFHLA), the Newest Vital Sign (NVS), the eHealth Literacy Scale (eHEALS), the Health Literacy Screening Question Methodologies (HLSQM) [16]. Generally, the TOFHLA and REALM tests are regarded as the gold standards for assessing the health literacy of patients [16]. The TOFHLA is used to measure patients comprehension towards health information and characterizes them as having adequate, marginal or inadequate health literacy [15]. The REALM test is the most commonly used health literacy assessment tool in the clinical setting. It tests the ability of patients to read and pronounce common medical terms [17].

While the morbidity and mortality associated with communicable diseases has been steadily declining for Beijing residents, new threats have continued to emerge in the last ten years including SARs and influenza H5N1 and H7N9 [18-23]. In order to formulate appropriate prevention/control and communication strategies it is important to understand the level of CDHL level of Beijing residents. Therefore, this new study aimed to evaluate CDHL levels of Beijing residents towards three key areas: knowledge, adoption of preventative measures/behaviours, and health skills. The distinction between the three areas is based on the health literacy definition of the WHO [6, 7].

\section{Methods}

\section{Instrument development}

The study aimed to measure and assesses health literacy. Items for the questionnaire were identified following a review of the published research. Chinese studies that explored the knowledge attitude, and practices of participants related to infectious diseases prevention and control were reviewed for possible variables. In addition, variables from the National Health Literacy Survey [24-27] that measured residents' level of basic knowledge, adoption of preventative measures and behaviors, or health skills regarding common communicable diseases were extracted. In order to identify the most contextually appropriate variables, only studies conducted in Mainland China were utilized.

The items that were chosen for inclusion were discussed and evaluated by a small group of professionals, including three clinical doctors and three public health experts from the field of infectious diseases treatment and prevention. The three clinical doctors worked in the infectious diseases department of an infectious diseases hospital, a tertiary hospital and a secondary hospital within the Beijing region respectively, and the three public health experts were from Beijing Center for Diseases Prevention and Control (CDC), a district CDC office, and a community health center. Following the panel discussion, a total of 25 items were chosen for inclusion. The final questionnaire consisted of three sections that measured: knowledge (8 items), adoption of preventative measures and behaviors (12 items), and health skills (5 items).

The final survey was available in Chinese and took five to ten minutes to be completed. Values were assigned to each of the questions: (1) one point for a correct or positive answer; and (2) zero points if the answer to the question was incorrect or negative. For the item "How many days did you do physical activities more than 30 min per day in the past one week?" one point was assigned if participants answered " $\geq 3$ days".

\section{Subjects and survey design}

A multistage stratified sampling approach was used to recruit participants. In 2008, The National Health Literacy Survey showed the expected percentage of people with adequate health literacy was $21.82 \%$ among city residents. The percentage was represented by symbol $\pi$ and the numerical value was 0.2182 [17]. The sample size of each subgroup was calculated by the function $n=\mu_{\alpha}^{2} \times \pi(1-\pi) /$ $\delta^{2} \times$ deff. The confidence interval (CI) was $\pm 10 \%$, maximum permissible error $(\delta)=0.1 \pi, \mu_{\alpha}=1.96$, and the design effect of complex sampling (deff) $=1.5$, which was used to adjust the effectiveness loss of complex sampling instead of random sampling. Therefore the minimum sample size of each subgroup was 2,065. Considering the differences among different age groups (18-29, 30-39, $40-49,50-59$ and $60+$ ), a total of five subgroups were identified. The total sample size of the five subgroups was expected to be $10,325(2,065 /$ subgroup $\times 5)$. Taking into consideration the response rates and efficiency rates of the questionnaire, the actual sample size was increased by $5 \%$ to a total of 10,841 .

There are 16 districts in Beijing, which are divided into urban and suburban districts based on population density. The population density was $>6548$ people per $\mathrm{km}^{2}$ in the urban districts and $\leq 1305.4$ people per $\mathrm{km}^{2}$ in the suburban districts. Six districts including three urban districts and three suburban districts were chosen to be sampled. Five towns or streets were randomly selected in each district, and five resident committees or villages were randomly selected in each town or street. In total, 150 residents' committees or villages were confirmed as survey locations. In every location, about 73 residents were randomly selected as subjects based on the name lists of residents acquired from residents' committees. Participants were resident's aged $\geq 18$ years that were able and willing to give their informed consent to participate and who had continuously lived in Beijing for more than half a year. Participants were excluded if they 
were foreigners, residents of Hong Kong, Macau or Taiwan, or were unable to communicate in Mandarin.

\section{Data collection}

The survey was conducted between December 2010 and January 2011. Participants were asked to complete the questionnaire by themselves or with the help of trained study staff if they had difficulty with reading or writing.

\section{Statistical analysis}

The database was established in Epidata 3.1, and analyzed using SPSS 11.5. Based on the score distribution, the average score of participants whose percentages were the closest to the top $25 \%$ and bottom $25 \%$ seperately were treated as the two cut points. The discrimination index (D) was calculated by taking the average score of the top $23.8 \%$ of participants $(\mathrm{PH}$, score $\geq 19)$ minus that of the bottom $22.9 \%$ (PL, score $\leq 12$ ). Reliability was calculated by internal consistency measures, using Cronbach's alpha formula. Inter-scale correlations were calculated by the means of Pearson's correlation coeffcients. Confirmation factor analyses were conducted to verify the scale's construct validity. Confirmatory factor analysis was implemented by the Amos 7. Cut-point of adequate health literacy was determined via receiver operating characteristic (ROC) analyses based on their educational level. Frequencies were calculated for categorical variables. One-way ANOVA was used to compare the differences of health literacy scores between subgroups. The Pearson $\chi^{2}$ test was used to compare the different proportions of respondents with CDHL in different groups. Multivariate unconditional logistic regression analysis was conducted to determine factors associated with the CDHL level. The variables with $P<0.10$ in univariate analysis were included in multivariate analysis. Backward logistic regression was conducted by removing variables with $P>0.10$. Statistical significance was defined as $P<0.05$.

\section{Ethics approval}

The study protocol was approved by the Research Ethic Committee of Beijing Center for Disease Prevention and Control.

\section{Results}

\section{Demographic characteristics}

The questionnaires were distributed to13287 Beijing residents, and 11052 of them completed the survey, with a response rate of $83.2 \%$. The demographic characteristics of the residents is included in Table 1.

\section{Reliability and validity of CDHL}

The average percentage of correct answer was $61.3 \%$. The overall discrimination index was 0.428 . Most of the items selected were answered with a moderate accuracy rate (average: $61.3 \%$ ) and with a good discrimination index (average: 0.428) (Table 2). Cronbach's alpha was 0.748 , indicating acceptable internal consistency for all of the items. Based on confirmatory factor analysis, the items were grouped into three subscales representing knowledge, adoption of preventative measures and behaviors, and health skills (GFI $=0.95$, TLI $=0.81$, AGFI $=$ 0.94, RMSEA = 0.046). (GFI, goodness-of-fit index; TLI, Tucker-Lewis index; AGFI, adjusted goodness-of-fit index; RMSEA, root mean square error of approximation). For further testing of the dimensionality of CDHL, correlations of the subscales and the Total Score were examined by means of Pearson correlation coefficient. Correlations of the subscales and the Total Score is significant $(P<0.01)$, and all the three subscales correlate strongly with the Total Score (Table 3).

\section{ROC analysis}

An ROC analysis was used to classify the levels of CDHL. The ROC curve is a graph of sensitivity (y-axis) versus 1 - specificity ( $x$-axis). Maximizing sensitivity corresponds to some large y value on the ROC curve. Maximizing specificity corresponds to a small $\mathrm{x}$ value on the ROC curve. Thus a good first choice for a test cutoff value is that value which corresponds to a point on the ROC curve nearest to the upper left corner of the ROC graph. In this study, comparisons by education level indicated a cut-point of 16.5 for differentiating respondents with college education versus no college education (area under the curve $=0.69$, sensitivity $=0.61$, specificity $=$ $0.68)$. Based on the analysis, participants were classified into two groups: inadequate health literacy (score $\leq 16$ ), and adequate health literacy (score $\geq 17$ ).

\section{CDHL level description}

The mean CDHL score for participants was 15.28. The percentage of those who were identified as having adequate CDHL was $41 \%$. The percentage with adequate CDHL was significantly higher in female $(42.4 \%)$ than that in male $(39.5 \%)(P=0.002)$. The percentage also increased with higher education levels. Participants aged between 30 and 39 years recorded the highest percentage of adequate CDHL ( $49 \%$ ), by contrast, the percentage of residents aged $>60$ was the lowest $(29.8 \%)$. Urban residents $(48.3 \%)$ were significantly more likely to have adequate health knowledge compared to participants residing in suburban areas $(P<0.001)$ (Table 1$)$.

\section{Factors associated with overall CDHL}

The following factors were found to significantly impact the levels of CDHL according to the multiple logistic regression: gender, age-group, highest level of education, occupation, and self-reported health status and region. Females were more likely to have adequate CDHL 
Table 1 Health literacy score and Percentage of adequate health literacy by Participant characteristics

\begin{tabular}{|c|c|c|c|c|c|c|c|c|}
\hline \multicolumn{2}{|c|}{ Participant characteristics } & Number & \multicolumn{3}{|c|}{ Health literacy score } & \multicolumn{3}{|c|}{ Percentage of adequate health literacy (score $>=17$ ) } \\
\hline Gender & & & Mean & Std. & $P$ & $\mathrm{n}$ & $\%$ & $P$ \\
\hline & male & 5344 & 15.1 & 4.11 & $<0.001$ & 2112 & 39.5 & 0.002 \\
\hline & female & 5701 & 15.44 & 4.02 & & 2417 & 42.4 & \\
\hline \multicolumn{9}{|c|}{ Nationality } \\
\hline & Han majority & 10246 & 15.28 & 4.09 & 0.582 & 4219 & 41.2 & 0.244 \\
\hline & The minority & 806 & 15.36 & 3.76 & & 315 & 39.1 & \\
\hline \multicolumn{9}{|c|}{ Age group } \\
\hline & $18-29$ & 2239 & 15.90 & 3.82 & $<0.001$ & 1042 & 46.5 & $<0.001$ \\
\hline & $30-39$ & 2180 & 16.09 & 3.85 & & 1069 & 49 & \\
\hline & $40-49$ & 2195 & 15.53 & 3.68 & & 910 & 41.5 & \\
\hline & $50-59$ & 2278 & 15.02 & 4.08 & & 870 & 38.2 & \\
\hline & $60-$ & 2160 & 13.86 & 4.49 & & 643 & 29.8 & \\
\hline \multicolumn{9}{|c|}{ Highest level of education } \\
\hline & illiteracy & 295 & 9.88 & 4.16 & $<0.001$ & 17 & 5.8 & $<0.001$ \\
\hline & primary school & 1084 & 12.28 & 4.08 & & 162 & 14.9 & \\
\hline & junior high school & 3008 & 14.34 & 3.77 & & 867 & 28.8 & \\
\hline & senior high school & 3194 & 15.71 & 3.63 & & 1390 & 43.5 & \\
\hline & college or above & 3462 & 17.12 & 3.47 & & 2098 & 60.6 & \\
\hline \multicolumn{9}{|c|}{ Occupation } \\
\hline & students & 378 & 15.86 & 3.96 & $<0.001$ & 190 & 50.3 & $<0.001$ \\
\hline & peasants & 2973 & 13.81 & 4.14 & & 779 & 26.2 & \\
\hline & manual workers & 289 & 13.94 & 3.97 & & 75 & 26 & \\
\hline & employee of enterprise & 1888 & 16.53 & 3.49 & & 1008 & 53.4 & \\
\hline & migrant workers & 325 & 14.49 & 4.05 & & 104 & 32 & \\
\hline & service workers & 887 & 15.26 & 3.79 & & 355 & 40 & \\
\hline & civil servants and publicinstitutions' staff & 1116 & 16.92 & 3.59 & & 652 & 58.4 & \\
\hline & healthcare workers & 303 & 18.96 & 3.25 & & 236 & 77.9 & \\
\hline & retirees & 1854 & 15.32 & 3.91 & & 747 & 40.3 & \\
\hline & people waiting for employment & 826 & 14.33 & 4.10 & & 265 & 32.1 & \\
\hline & others & 213 & 16.46 & 3.45 & & 123 & 57.7 & \\
\hline \multicolumn{9}{|c|}{ Self-reported health status } \\
\hline & excellent & 2478 & 16.26 & 3.86 & $<0.001$ & 1279 & 51.6 & $<0.001$ \\
\hline & good & 3980 & 15.59 & 3.92 & & 1728 & 43.4 & \\
\hline & normal & 4009 & 14.71 & 4.02 & & 1374 & 34.3 & \\
\hline & bad & 503 & 12.94 & 4.72 & & 132 & 26.2 & \\
\hline & very bad & 78 & 12.83 & 4.39 & & 18 & 23.1 & \\
\hline \multicolumn{9}{|l|}{ Region } \\
\hline & urban & 5729 & 15.97 & 3.90 & $<0.001$ & 2767 & 48.3 & $<0.001$ \\
\hline & suburb & 5323 & 14.54 & 4.12 & & 1767 & 33.2 & \\
\hline Overall & & 11052 & 15.28 & 4.07 & & 4534 & 41 & \\
\hline
\end{tabular}


Table 2 Percentage of correct answer, discrimination index, and item-total correlation of health literacy items

\begin{tabular}{|c|c|c|c|c|c|c|}
\hline & Items & $\begin{array}{l}\% \\
\text { correct }\end{array}$ & $\mathrm{PH}$ & $\mathrm{PL}$ & $\mathrm{D}$ & $\begin{array}{l}\text { Item-total } \\
\text { correlation }\end{array}$ \\
\hline \multirow[t]{8}{*}{ Knowledge } & What is the normal body temperature? & 36.3 & 0.221 & 0.523 & 0.302 & 0.232 \\
\hline & What diseases do vaccines protect against? & 86.6 & 0.702 & 0.984 & 0.283 & 0.367 \\
\hline & Which is the best way for influenza prevention? & 79.1 & 0.574 & 0.952 & 0.378 & 0.371 \\
\hline & Which is the best way for measles prevention? & 46.5 & 0.286 & 0.681 & 0.395 & 0.287 \\
\hline & What are the typical clinical symptoms of tuberculosis? & 74.7 & 0.540 & 0.943 & 0.403 & 0.377 \\
\hline & How is hepatitis A spread? & 48.6 & 0.293 & 0.731 & 0.438 & 0.327 \\
\hline & Which of the following is the correct path for the transmission of hepatitis B? & 23.9 & 0.078 & 0.512 & 0.433 & 0.360 \\
\hline & Which of the following is the correct path for the transmission of HIV? & 39.6 & 0.138 & 0.698 & 0.560 & 0.416 \\
\hline \multirow[t]{13}{*}{$\begin{array}{l}\text { Preventative measures } \\
\text { and behaviors }\end{array}$} & $\begin{array}{l}\text { How many days did you do physical activities more than } 30 \text { min per day in } \\
\text { the past week? }\end{array}$ & 38.1 & 0.280 & 0.498 & 0.218 & 0.173 \\
\hline & Do you spit up phlegm in public? & 93.9 & 0.818 & 0.996 & 0.178 & 0.337 \\
\hline & Do you cover up when you want to sneeze or cough? & 93.4 & 0.806 & 0.994 & 0.189 & 0.343 \\
\hline & Do you wash your hands before eating, after using the bathroom? & 54.4 & 0.258 & 0.840 & 0.582 & 0.445 \\
\hline & Do you wear mask when visiting someone at the hospital? & 20.9 & 0.063 & 0.420 & 0.357 & 0.322 \\
\hline & Do you often open the windows to keep & 86.4 & 0.688 & 0.977 & 0.289 & 0.348 \\
\hline & The air circulation during the respiratory infectious diseases epidemics? & & & & & \\
\hline & Do you separate raw and cooked food when cooking or preserving them? & 77.2 & 0.549 & 0.942 & 0.393 & 0.375 \\
\hline & Will you visit restaurants with poor sanitation? & 28.8 & 0.109 & 0.568 & 0.459 & 0.371 \\
\hline & Do you share towels with others? & 66.6 & 0.410 & 0.886 & 0.476 & 0.391 \\
\hline & Do you visit a dentist at an irregular outpatient clinic? & 92.4 & 0.832 & 0.988 & 0.156 & 0.263 \\
\hline & Do you uptake rabies vaccine after a dog or cat bite? & 76.1 & 0.530 & 0.938 & 0.408 & 0.379 \\
\hline & $\begin{array}{l}\text { Will you pay attention to infectious disease epidemics at your destination } \\
\text { when you want to travel? }\end{array}$ & 72.8 & 0.421 & 0.935 & 0.514 & 0.458 \\
\hline \multirow[t]{5}{*}{ Health skills } & Can you easily get the information about infectious diseases? & 41.2 & 0.091 & 0.817 & 0.725 & 0.534 \\
\hline & Can you read drug instructions? & 48.1 & 0.115 & 0.889 & 0.773 & 0.562 \\
\hline & Can you easily read popular science readings about infectious diseases? & 48.3 & 0.096 & 0.916 & 0.820 & 0.598 \\
\hline & Can you read laboratory sheets? & 47.9 & 0.190 & 0.818 & 0.628 & 0.468 \\
\hline & Can you use the thermometer? & 76.9 & 0.579 & 0.927 & 0.348 & 0.341 \\
\hline Overall & & 61.3 & 0.387 & 0.815 & 0.428 & \\
\hline
\end{tabular}

$(\mathrm{OR}=1.24, P<0.001)$. By age group, residents aged 30-39 (OR = 1.39, $P<0.001), 40-49(\mathrm{OR}=1.26, P=$ $0.001)$ and $50-59(\mathrm{OR}=1.32, P<0.001)$ possessed significantly higher level of CDHL when compared to the participant's aged 18-29. Residents aged more than 60 years old also showed higher CDHL level, however, the difference was not statistical significant. Not surprising, the level of CDHL increased with increases in self-reported health status. Among different occupations, health workers possessed the highest CDHL level $(\mathrm{OR}=3.13, \quad P<0.001)$, while manual workers have the lowest CDHL level $(\mathrm{OR}=0.60, P=0.005)$. The CDHL level lowered with the decreasing of selfreported health status. The residents lived in the suburb possessed significantly lower CDHL level than those who lived in the urban areas (Table 4).

\section{Discussion}

Numerous studies examining the issue of health literacy have been conducted since the concept was first introduced [28-31]. In 2007, the National Health Literacy

Table 3 Inter-Scale Correlations (Pearson's correlation)

\begin{tabular}{|c|c|c|c|c|}
\hline & Knowledge & $\begin{array}{l}\text { Preventative } \\
\text { measures and } \\
\text { behaviors }\end{array}$ & $\begin{array}{l}\text { Health } \\
\text { skills }\end{array}$ & $\begin{array}{l}\text { Total } \\
\text { score }\end{array}$ \\
\hline Knowledge & $1^{a}$ & $0.312^{a}$ & $0.326^{a}$ & $0.692^{a}$ \\
\hline $\begin{array}{l}\text { Preventative measures } \\
\text { and behaviors }\end{array}$ & $0.312^{a}$ & $1^{a}$ & $0.439^{a}$ & $0.797^{\mathrm{a}}$ \\
\hline Health skills & $0.326^{a}$ & $0.439^{a}$ & 1.000 & $0.746^{a}$ \\
\hline Total score & $0.692^{a}$ & $0.797^{\mathrm{a}}$ & $0.746^{\mathrm{a}}$ & 1.000 \\
\hline
\end{tabular}

${ }^{\mathrm{a}}$ Correlation is significant at the 0.01 level 
Table 4 Multiple logistic regressions for the factors related to $\mathrm{CDHL}$

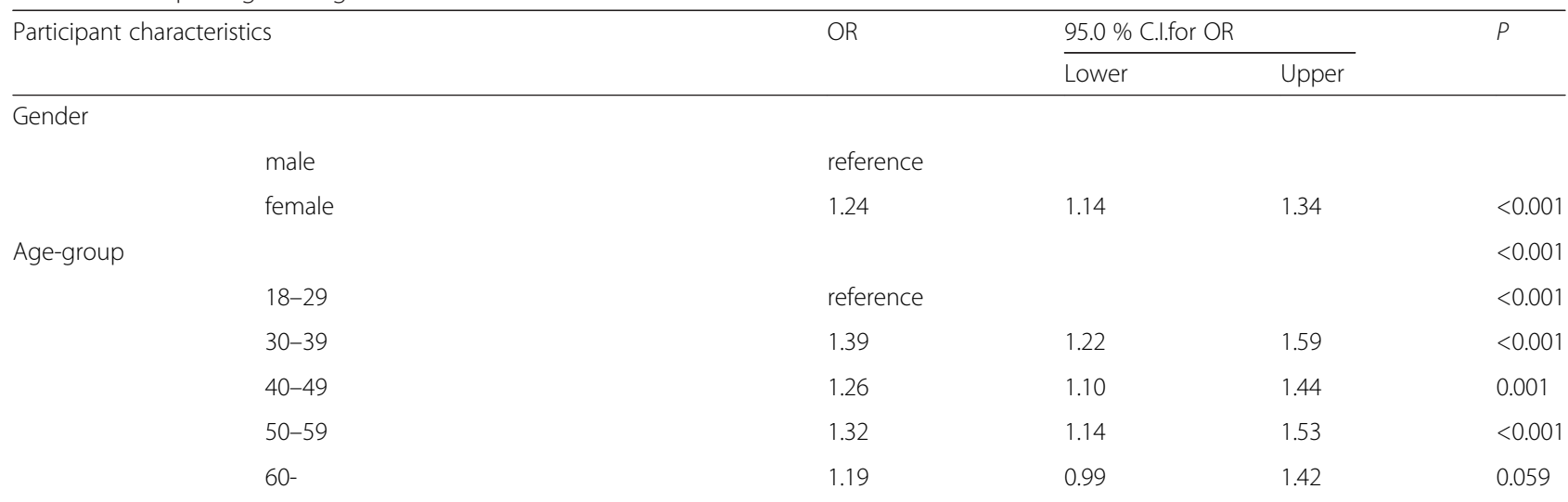

Highest level of education

\section{illiteracy \\ primary school \\ junior high school \\ senior high school \\ college or above}

Occupation

students
peasants
manual workers
employee of enterprise
migrant workers
service workers
civil servants and public institutions' staff
healthcare workers
retirees
people waiting for employment
others

Self-reported health status

excellent
good
normal
bad
very bad

Region

urban

suburb

$\begin{array}{llll}\text { reference } & & & <0.001 \\ 2.74 & 1.63 & 4.61 & <0.001 \\ 6.07 & 3.67 & 10.05 & <0.001 \\ 10.90 & 6.56 & 18.11 & <0.001 \\ 19.18 & 11.47 & 32.07 & <0.001\end{array}$

reference $\quad<0.001$

$\begin{array}{llll}0.93 & 0.72 & 1.21 & 0.592\end{array}$

$\begin{array}{llll}0.60 & 0.42 & 0.86 & 0.005\end{array}$

$\begin{array}{llll}1.09 & 0.86 & 1.38 & 0.485\end{array}$

$\begin{array}{llll}0.73 & 0.52 & 1.01 & 0.061\end{array}$

$\begin{array}{llll}0.85 & 0.65 & 1.10 & 0.218\end{array}$

$\begin{array}{llll}1.20 & 0.93 & 1.54 & 0.169\end{array}$

$\begin{array}{llll}3.13 & 2.20 & 4.46 & <0.001\end{array}$

$\begin{array}{llll}1.26 & 0.96 & 1.65 & 0.091\end{array}$

$\begin{array}{llll}0.82 & 0.62 & 1.08 & 0.160\end{array}$

$\begin{array}{llll}1.53 & 1.07 & 2.19 & 0.020\end{array}$

$\begin{array}{llll}\text { reference } & & & <0.001 \\ 0.65 & 0.59 & 0.73 & <0.001 \\ 0.52 & 0.47 & 0.59 & <0.001 \\ 0.52 & 0.41 & 0.66 & <0.001 \\ 0.46 & 0.26 & 0.81 & 0.007\end{array}$

reference

0.87

0.79

0.97

0.010
Survey was launched to investigate the levels of health related knowledge and behaviors of Chinese residents $[32,17]$. In addition, Xinyin Sun undertook a study measuring the health literacy of infectious respiratory diseases in Beijing [33]. However, most studies conducted to date have failed to cover all three elements of health literacy. We are the first group to explore the issue of health literacy amongst residents of Beijing.

From our results, we found that the proportion of Beijing residents with adequate CDHL (49.0\%) was comparatively higher when compared to the national average of $13.64 \%$ [17]. Rates were particularly low amongst 
participants: (1) residing in the suburbs; (2) aged 60 years and above; (3) who were mainly engaged in manual labor, and (4) who had completed less than five years of education.

Results from our study showed that gender, age-group, highest level of education, occupation, self-reported health status and region were factors related to the CDHL level significantly. Large-scale surveys of adult health literacy have previously reported associations between at-risk groups and low general literacy skills [34].

People with lower education level demonstrate lower health literacy in comparison with people with higher education level $[35,4,36]$. Low health literacy may be a barrier in access to health information and health care medication use and the prevention of disease [4]. Therefore, low health literacy has been associated with a range of poor health outcomes [37, 38, 35]. Consequently, improving the education level of residents is a key factor in improving CDHL. At the present time, multiple intervention strategies should be applied to residents of different education levels, including timely and accurate delivery of information to the public during a disease outbreak, and additional description of who is at risk, the nature of that risk, and what can be done to avoid exposure and manage illness [39].

The percentage of adequate CDHL of those who were over 60 years old was the lowest of all age subgroups in this study (Table 1). Several factors may affect CDHL levels in those over 60. The first is the decline of memory and verbal fluency, which are strongly associated with health literacy [40]. The second is that lower education levels in those over 60 years old might limit their abilities to obtain knowledge of CDHL. In a cross-sectional survey conducted by Li Wu in China, the proportion of the elderly who had six years or more of schooling was only $19.0 \%$ [41]. The third factor is that the decline of cognition which has an obvious and direct impact on reading comprehension may impose restrictions on acquiring knowledge of communicable disease prevention and control from mass medias $[42,43]$.

The percentage of adequate CDHL of residents in suburbs was significantly lower than those of residents in urban areas (Table 1). This might be related to their economic status, the allocation of medical resources and the accessibility of CDHL information. Generally, the economic level and education resources in the suburbs were lower and less than in the urban areas in China. It is well established that poverty will directly affect peoples' ability to make "good" decisions, including those related to their health [44]. Meanwhile less education resources will limit the education level of the local residents. To date, health education and promotion efforts have mainly been launched in urban areas. To change this situation, the publicity of control and prevention knowledge of communicable diseases should be given intensively in the suburbs considering the local epidemic characteristics.

Our study has a number of key strengths. Firstly, in order to improve the practical applicability and tolerance of the subjects, the questionnaire was professionally administered in five to ten minutes. It demonstrated good internal consistency and yielded comparable results. Secondly, the majority of previous investigations have usually focused on assessing the health literacy in limited fields [9, 33], or of certain populations [45, 46]. While our study involved a range of participants from different areas. The research findings were more representative of the overall CDHL in Beijing.

Along with the concept of eHealth literacy has been developed [47], some specific skills to seeking and understanding information of health are increasingly important. However, they may not be familiar to the elders. Consequently, some traditionnal channels, such as television programs, advice from doctors and suggestions from friends remain the main avenues for the elders to improve their health literacy [48], which limits them to acquire health related knowledge as easily as young people do.

\section{Conclusions}

Although the method adopted in our study might be different from other studies, it supplied a hint that the CDHL level of residents in Beijing was relatively low compared with those of other cities [49]. In view of the factors that lead to the low CDHL in elder people, measures aiming at improving their CDHL should be carried out. The health and healthcare related information of communicable diseases to the elder adults must be designed beyond vocabulary simplification and specifically to limit the demand on memory and verbal fluency more comprehensively. Meanwhile, public health workers need to consider the possibility of cognitive dysfunction in the elder adults, and adapt their information giving accordingly through multiple medium.

\section{Abbreviations \\ CDHL: Communicable diseases health literacy; WHO: World Health Organization; AMA: American Medical Association; TOFHLA: the Test of Functional Health Literacy in Adults; REALM-R: the Shortened Rapid Estimate of Adult Literacy in Medicine; S-TOFHLA: the Shortened Test of Functional Health Literacy in Adults; NVS: the Newest Vital Sign; eHEALS: the eHealth Literacy Scale; HLSQM: the Health Literacy Screening Question Methodologies; CDC: Diseases Prevention and Control; ROC: Receiver operating characteristic; GFI: Goodness-of-fit index; TLI: Tucker-Lewis index; AGFI: Adjusted goodness-of-fit index; RMSEA: Root mean square error of approximation.}

Competing interests

The authors declare that they have no competing interests. 


\section{Authors' contributions}

Conceived and designed the study:DZ, SW, PY, QW. Study implementation: DZ, SW. Data analysis: SW, YZ. Drafted the manuscript: DZ, SW. Reviewed the paper: DZ, SW, YZ, PY, CRM, HS, QW. All authors read and approved the final manuscript.

\section{Acknowledgements}

The authors would like to thank all the people who participated in this study for their trust and cooperation making this project possible. Special thanks to the Center for Disease Prevention and Control in 16 districts in Beijing and the School of Public Health and Community Medicine of the University of New South Wales for the staff who worked hand in hand with the authors and excellent technical assistance during the whole study period. We are sincerely grateful to the Beijing Municipal Science \& Technology Commission (No. Z131100005613048) and the Capital Health Research and Development of Special (2014-1-1011) for funding this study.

\section{Author details}

${ }^{1}$ Beijing Center for Disease Prevention and Control, No.16 He Pingli Middle Street, Dongcheng District, Beijing 100013, China. ${ }^{2}$ School of Public Health and Community Medicine, UNSW Medicine, The University of New South Wales, Sydney, Australia.

\section{Received: 13 April 2015 Accepted: 13 August 2015}

\section{Published online: 19 August 2015}

\section{References}

1. Kickbusch I. Health literacy: engaging in a political debate. Int J Public Health. 2009:54(3):131-2. doi:10.1007/s00038-009-7073-1.

2. Wills J. Health literacy: new packaging for health education or radical movement? Int J Public Health. 2009;54(1):3-4. doi:10.1007/s00038-008-8141-7.

3. Abel T. Measuring health literacy: moving towards a health - promotion perspective. Int J Public Health. 2008;53(4):169-70. doi:10.1007/s00038-008-0242-9.

4. Nutbeam D. The evolving concept of health literacy. Soc Sci Med. 2008;67(12):2072-8. doi:10.1016/j.socscimed.2008.09.050.

5. Coulter A, Ellins J. Effectiveness of strategies for informing, educating, and involving patients. BMJ. 2007;335(7609):24-7. doi:10.1136/bmj.39246.581169.80.

6. Smith BJ, Tang KC, Nutbeam D. WHO Health Promotion Glossary: new terms. Health Promot Int. 2006;21(4):340-5. doi:10.1093/heapro/dal033.

7. Nutbeam D. Health literacy as a public health goal: a challenge for contemporary health education and communication strategies into the 21st Century. Health Promot Int. 2000;15(3):259-67.

8. Meuser TM, Carr DB, Irmiter C, Schwartzberg JG, Ulfarsson GF. The American Medical Association Older Driver Curriculum for health professionals: changes in trainee confidence, attitudes, and practice behavior. Gerontol Geriatr Educ. 2010;31(4):290-309. doi:10.1080/02701960.2010.528273.

9. Al Sayah F, Majumdar SR, Williams B, Robertson S, Johnson JA. Health literacy and health outcomes in diabetes: a systematic review. J Gen Intern Med. 2013;28(3):444-52. doi:10.1007/s11606-012-2241-z.

10. Osborn CY, Paasche-Orlow MK, Bailey SC, Wolf MS. The mechanisms linking health literacy to behavior and health status. Am J Health Behav. 2011;35(1):118-28.

11. Loke YK, Hinz I, Wang X, Rowlands G, Scott D, Salter C. Impact of health literacy in patients with chronic musculoskeletal disease-systematic review. PLoS One. 2012;7(7), e40210. doi:10.1371/journal.pone.0040210.

12. Sun $X Y$, Shi $Y H$, Zeng $Q Q$, Wang $Y L$, Du WJ, Wei NF, et al. Determinants of health literacy and health behavior regarding infectious respiratory diseases: a pathway model. BMC Public Health. 2013;13:261. doi:10.1186/1471-2458-13-261.

13. Nielsen-Bohlman L, Institute of Medicine (U.S.). Committee on Health Literacy. Health literacy : a prescription to end confusion. Washington, D.C.: National Academies Press; 2004.

14. Davis TC, Crouch MA, Long SW, Jackson RH, Bates P, George RB, et al. Rapid assessment of literacy levels of adult primary care patients. Fam Med. 1991;23(6):433-5.

15. Parker RM, Baker DW, Williams MV, Nurss JR. The test of functional health literacy in adults: a new instrument for measuring patients' literacy skills. J Gen Intern Med. 1995;10(10):537-41.

16. Collins SA, Currie LM, Bakken S, Vawdrey DK, Stone PW. Health literacy screening instruments for eHealth applications: a systematic review. J Biomed Inform. 2012;45(3):598-607. doi:10.1016/j.jbi.2012.04.001.
17. Wang P, Mao QA, Tao MX, Tian XY, Li YH, Qian L, et al. Survey in the status of health literacy of Chinese residents in 2008. Chinese J Health Educ. 2010;26(4):4.

18. Liang WN, Zhu ZH, Guo JY, Liu ZJ, He X, Zhou WG, et al. Severe acute respiratory syndrome, Beijing, 2003. Emerg Infect Dis. 2004;10(1):25-31. doi:10.3201/eid1001.030553.

19. Shen Z, Ning F, Zhou WG, He X, Lin CY, Chin DP, et al. Superspreading SARS events, Beijing, 2003. Emerg Infect Dis. 2004;10(2):256-60. doi:10.3201/eid1002.030732.

20. Wu J, Xu FJ, Zhou WG, Feikin DR, Lin CY, He X, et al. Risk factors for SARS among persons without known contact with SARS patients, Beijing, China. Emerg Infect Dis. 2004;10(2):210-6. doi:10.3201/ eid1002.030730

21. Pang XH, Yang P, Li S, Zhang L, Tian LL, Li Y, et al. Pandemic (H1N1) 2009 among quarantined close contacts, Beijing, People's Republic of China. Emerg Infect Dis. 2011;17(10):1824-30. doi:10.3201/eid1710.101344.

22. Wu J, Xu FJ, Lu L, Lu M, Miao L, Gao T, et al. Safety and effectiveness of a 2009 H1N1 vaccine in Beijing. N Engl J Med. 2010;363(25):2416-23. doi:10.1056/NEJMoa1006736

23. Chowell G, Simonsen L, Towers S, Miller MA, Viboud C. Transmission potential of influenza A/H7N9, February to May 2013, China. BMC Med. 2013;11:214. doi:10.1186/1741-7015-11-214.

24. Li XY, Du M, Wang QY, Gao T, Gao P, Shen YH, et al. Investigation on Knowledge, Attitude, and Practice About Infectious Diseases Among Teachers in Charge of the Class in Primary and Secondary Schools of Beijing. Pract Prev Med. 2008;15(1):16-18.

25. Wang QY, Li XY, Gao T, Gao P, Shen YH, Zhang SJ, et al. An investigation on knowledge, attitude and practice about prevention and control of infectious diseases among school health-care workers in Beijing. Capital J Public Health. 2008;2(1):3-6.

26. Shi WP, Shen HG, Liu LJ. Survey on KAP status of major infectious disease among migrants in Minhang District, Shanghai. Chinese J Health Educ. 2012;28(5):389-92.

27. Wang CC, Liu XF, Chen MN. KAP of infectious disease among medical and non-medical students. Chinese Ural Health Service Adm. 2010;30(8):684-86.

28. Hom JM, Lee JY, Divaris K, Baker AD, Vann Jr WF. Oral health literacy and knowledge among patients who are pregnant for the first time. J Am Dent Assoc. 2012;143(9):972-80.

29. Ganzer CA, Insel KC, Ritter LS. Associations between working memory, health literacy, and recall of the signs of stroke among older adults. J Neurosci Nurs. 2012;44(5):236-43. doi:10.1097/JNN.0b013e3182666231.

30. Weidmer BA, Brach C, Slaughter ME, Hays RD. Development of Items to Assess Patients' Health Literacy Experiences at Hospitals for the Consumer Assessment of Healthcare Providers and Systems (CAHPS) Hospital Survey. Med Care. 2012;50(9 Suppl 2):S12-21. doi:10.1097/MLR.0b013e31826524a0.

31. Osborn CY, Davis TC, Bailey SC, Wolf MS. Health literacy in the context of HIV treatment: introducing the Brief Estimate of Health Knowledge and Action (BEHKA)-HIV version. AIDS Behav. 2010;14(1):181-8. doi:10.1007/ s10461-008-9484-Z.

32. Zheng YD, Shi JH, Cao RX. Confirmative factor analysis in the health literacy questionnaire and its applications in Chinese residents. Beijing Da Xue Xue Bao. 2010;42(3):314-7.

33. Sun $X Y$, Chen J, Shi $Y H$, Zeng $Q Q$, Wei NF, Xie RQ, et al. Measuring health literacy regarding infectious respiratory diseases: a new skills-based instrument. PLoS One. 2013;8(5):e64153. doi:10.1371/journal.pone.0064153.

34. Rudd RK, I.; Yamamoto, K. Literacy and Health in America. Educational Testing Service 2004.

35. Howard DH, Sentell T, Gazmararian JA. Impact of health literacy on socioeconomic and racial differences in health in an elderly population. J Gen Intern Med. 2006;21(8):857-61. doi:10.1111/j.1525-1497.2006.00530.x.

36. Lee SY, Tsai TI, Tsai YW, Kuo KN. Health literacy, health status, and healthcare utilization of Taiwanese adults: results from a national survey. BMC Public Health. 2010;10:614. doi:10.1186/1471-2458-10-614.

37. Bennett IM, Chen J, Soroui JS, White S. The contribution of health literacy to disparities in self-rated health status and preventive health behaviors in older adults. Ann Fam Med. 2009;7(3):204-11. doi:10.1370/afm.940.

38. Berkman ND, Sheridan SL, Donahue KE, Halpern DJ, Crotty K. Low health literacy and health outcomes: an updated systematic review. Ann Intern Med. 2011;155(2):97-107. doi:10.7326/0003-4819-155-2-201107190-00005.

39. Lagasse LP, Rimal RN, Smith KC, Storey JD, Rhoades E, Barnett DJ, et al. How accessible was information about H1N1 flu? Literacy assessments of CDC 
guidance documents for different audiences. PLoS One. 2011;6(10):e23583. doi:10.1371/journal.pone.0023583.

40. Federman AD, Sano M, Wolf MS, Siu AL, Halm EA. Health literacy and cognitive performance in older adults. J Am Geriatr Soc. 2009;57(8):1475-80. doi:10.1111/j.1532-5415.2009.02347.x.

41. Wu L, Chen H, Hu Y, Xiang HY, Yu X, Zhang T, et al. Prevalence and associated factors of elder mistreatment in a rural community in People's Republic of China: a cross-sectional study. PLoS One. 2012;7(3):e33857. doi:10.1371/journal.pone.0033857.

42. Morrow D, Clark D, Tu W, Wu J, Weiner M, Steinley D, et al. Correlates of health literacy in patients with chronic heart failure. Gerontologist. 2006:46(5):669-76.

43. Weiss BD, Reed R, Kligman EW, Abyad A. Literacy and performance on the Mini-Mental State Examination. J Am Geriatr Soc. 1995;43(7):807-10.

44. Mani A, Mullainathan S, Shafir E, Zhao J. Poverty impedes cognitive function. Science. 2013;341(6149):976-80. doi:10.1126/science.1238041.

45. Garcia CH, Espinoza SE, Lichtenstein M, Hazuda HP. Health literacy associations between Hispanic elderly patients and their caregivers. J Health Commun. 2013;18 Suppl 1:256-72. doi:10.1080/10810730.2013.829135.

46. Dennison CR, McEntee ML, Samuel L, Johnson BJ, Rotman S, Kielty A, et al. Adequate health literacy is associated with higher heart failure knowledge and self-care confidence in hospitalized patients. J Cardiovasc Nurs. 2011;26(5):359-67. doi:10.1097/JCN.0b013e3181f16f88.

47. Norman CD, Skinner HA. eHealth Literacy: Essential Skills for Consumer Health in a Networked World. J Med Internet Res. 2006;8(2):e9. doi:10.2196/jmir.8.2.e9.

48. Aihara Y, Minai J. Barriers and catalysts of nutrition literacy among elderly Japanese people. Health Promot Int. 2011;26(4):421-31. doi:10.1093/heapro/dar005.

49. Sentell T, Braun KL. Low health literacy, limited English proficiency, and health status in Asians, Latinos, and other racial/ethnic groups in California. J Health Commun. 2012;17 Suppl 3:82-99. doi:10.1080/10810730.2012.712621.

\section{Submit your next manuscript to BioMed Central and take full advantage of:}

- Convenient online submission

- Thorough peer review

- No space constraints or color figure charges

- Immediate publication on acceptance

- Inclusion in PubMed, CAS, Scopus and Google Scholar

- Research which is freely available for redistribution 